\title{
Childhood injuries: A commission for human responsibilities is needed
}

A discussion at an Ethics Alive symposium raised the issue of a commission for human responsibilities. Human rights are constantly discussed in South Africa (SA). However, the focus is often on rights, while little attention is paid to corresponding duties and responsibilities.

The United Nations (UN) adopted the Universal Declaration of Human Rights (UDHR) $>50$ years ago. It is now time to reflect on a universal declaration of human responsibilities that would complement and strengthen the UDHR, with the objective of making this a better world. We consider the 1998 Declaration of Human Duties and Responsibilities (DHDR) in the context of violence against children in SA and call for a commission on human duties and responsibilities to complement and strengthen our Human Rights Commission.

\section{Declaration of Human Duties and Responsibilities}

The DHDR document was completed by global experts, including Nobel Prize laureates, with the assistance of the UN Organization for Education, Science and Culture (UNESCO) and the UN high commissioner for human rights, to revitalise the implementation of human rights. This was partly to celebrate the 50th anniversary of the UDHR. Justice Richard Goldstone, from SA, chaired this diverse group of scientists, artists and philosophers. ${ }^{[1]}$

Goldstone noted that the occasion was strongly motivated by the urgent need of the transition from a 'formal equality' to a 'substantial equality', in view of the desperate condition of so many unnoticed and disregarded people in the world: 'The recognition of human rights is insufficient, ... if such rights are to be realized it is necessary that they are enforceable .... There must be a duty on all relevant authorities and individuals to enforce those rights. ${ }^{[1]}$

\section{Childhood trauma}

Children worldwide are often the main victims of injury and violence, with $>1$ million succumbing to trauma annually, according to the World Health Organization (WHO)'s Global Burden of Disease 2004. ${ }^{[2]}$ Accidental injuries comprise the vast majority of the trauma, while the remainder constitutes violence aimed against children. Childhood deaths are only the tip of the iceberg, with vast numbers of children being left with physical and mental scarring, mutilation and disability. As expected, the greatest burden is carried by low- and middle-income countries and regions, where $>95 \%$ of all deaths of injured children occur. Unfortunately, child safety is poorly defined and there is a dire need to expand on the various categories.

The main causes of child mortality from 'accidental' injury are road traffic accidents (32\%), drowning (17\%) and burns (9\%), ${ }^{[2]}$ which are all highly preventable. Young children, especially, require continuous supervision, as they are not neurodevelopmentally mature to take care of their own safety. Risk factors that influence the likelihood of childhood injuries include an absent father, alcohol or substance abuse among caregivers, multiple siblings, and a large family, ${ }^{[2]}$ which are often present in previously disadvantaged areas. Therefore, it is vital to contextualise childhood injuries geographically and historically, even though child safety should be a priority in all societies. Creative and feasible interventions have been developed to mitigate child death and disability from injury. ${ }^{[3]}$
Very young children are the most vulnerable, as they lack the ability to assess dangerous objects or situations in their environment that they are unable to avoid, and for which they require the protection of mature individuals. Insufficient supervision of young children results in high levels of childhood morbidity and mortality. In many countries where children form the greater part of the population their special needs and interests are rarely considered.

The WHO defines violence as 'the intentional use of physical force or power, threatened or actual, against oneself, another person, or against a group or community that either results in or has a high likelihood of resulting in injury, death, psychological harm, maldevelopment or deprivation. ${ }^{[4]}$ This definition revolves around the intentionality of the act and is not dependent on the injury it causes. WHO definitions of child abuse or maltreatment are much wider, including physical and/or emotional ill-treatment, sexual abuse, neglect or negligent treatment, and commercial or other exploitation that results in actual or potential harm to the child's health, survival, development or dignity in the context of the relationship of responsibility, trust and power. ${ }^{[4]}$ At Red Cross War Memorial Children's Hospital, Cape Town, SA $~ 10000$ injured children $\leq 13$ years of age are treated annually, including those who are physically and/or sexually abused. Infants and very young children are at the greatest risk of being murdered. ${ }^{[2]}$

The single most important protection against exposure to violence is a robust relationship with a competent, caring, positive adult, usually a parent. However, such a person is often absent in previously disadvantaged communities and the carers frequently cannot be present owing to long hours in low-income jobs, which may be far from their communities ${ }^{[5]}$ These care providers may have been victimised and scarred by emotional trauma and cannot protect their children and keep them secure. People from communities where excessive violence takes place are often caught up in a web of helplessness and frustration, resulting in failure to safeguard their own children. ${ }^{[6]}$

During the 21st century, violence has taken the format of a 'public health epidemic. ${ }^{\text {'[2] }}$ Many young children are constantly exposed to violence in their families, communities, and the social media, which indulge children with violence. Children in developed countries are exposed to 16000 simulated murders and 200000 acts of violence in the media before reaching adulthood. ${ }^{[5]} \mathrm{A}$ compounding factor is that the committed violence is usually associated with so-called positive role models, with little sympathy for the victim and attention to the dire consequences of the inflicted injuries. Infants and toddlers who continuously witness violence in their environment display excessive irritability, immature behaviour, sleep disturbances, emotional distress, fear of being alone and regression in toileting and language.$^{[6]}$ Almost two decades ago, the public health community in the USA, including a wide range of paediatricians, psychiatrists and psychologists, found that there were $>1000$ studies indicating a causal relationship between media (television, films, video games) violence and aggressive behaviour in certain children. ${ }^{[7]}$

The Childsafe Child Injury Surveillance System at Red Cross War Memorial Children's Hospital indicates that the vast majority of injuries in young children occur in and around the home, while older school-going children are the most vulnerable on their way to and from school. Most societies abhor violence against young children, and abused children often receive sensational media attention. 
However, it is thought provoking to realise that so-called accidental injuries and maltreatment of children have many identical risk and resilience factors. ${ }^{[8]}$ Violence prevention strategies have typically targeted people and behaviour, while strategies directed at accidental injuries have usually focused on promoting a change in materials and environment. Child safety will only advance with close collaboration of both these approaches. Many risk factors for childhood injury are amenable to prevention strategies, including community factors comprising, inter alia, poverty, social capital and other societal factors. ${ }^{[2]}$

In SA, alcohol is a major risk factor for many types of trauma, accidental and non-accidental, with studies indicating that alcohol plays a role in up to $70 \%$ of any sustained injuries. Many well-proven strategies can prevent and diminish the negative effects of substance abuse among children; early intervention is a key component of successful programmes. ${ }^{[9]}$

\section{Discussion}

Many programmes address childhood infectious diseases, malnutrition and dehydration. However, childhood injury remains neglected, which is particularly sad as it is largely preventable. ${ }^{[3]}$ Many childhood injury risk factors can be easily addressed, creating awareness. Interventions require participation of all role players to pressurise political will to make child safety-promoting changes. Vigorous promotion of awareness of the plight of so many children is essential to reduce the enormous burden of childhood injuries.

\section{A prudent time for a commission on human responsibilities}

There is a substantial difference between duty and responsibility as defined in the DHDR. ${ }^{[1]}$ Duty refers to an ethical or moral obligation, while responsibility refers to a legally binding obligation under international law. The DHDR details a wide range of responsibilities.

All members of the global community have individual and collective duties and responsibilities aimed at promoting human rights and fundamental freedoms. The most crucial article in the declaration (chapter 2) is that of the right to life and human safety. ${ }^{[1]}$ Everyone has the right to life, liberty and safety of person. In particular, chapter 3 of the DHDR ${ }^{[1]}$ draws attention to intergenerational responsibility. The duty and responsibility to protect each human life is stated clearly, making everyone responsible to protect all lives that are in danger, distress or need.
These DHDR articles provide the ideal framework to create a commission on human duties and responsibilities in SA, which could be established as an arm of the current Human Rights Commission, but with the significant difference of focusing on what society should and can do rather than what it should receive.

\section{Conclusion}

A key element of formulating the DHDR has been the duty and responsibility for the potential consequences of our actions for future generations. 'The rights of these future generations are the duties of present generations', according to Federico Mayor, former Director General of UNESCO. Therefore, the right to peace and the right to live in a safe environment must be fully recognised and guaranteed. Children will never be safe as long the adult society does not act responsibly.

\section{A B van As}

Childsafe, Cape Town; and Trauma Unit, Red Cross War Memorial Children's Hospital, and Division of Paediatric Surgery, Faculty of

Health Sciences, University of Cape Town, South Africa

sebastian.vanas@uct.ac.za

\section{A Dhai}

Steve Biko Centre for Bioethics, Faculty of Health Sciences, University of the Witwatersrand, Johannesburg, South Africa

\footnotetext{
Inter Action Council. A Universal Declaration of Human Responsibilities. http://interactioncouncil.org/ universal-declaration-human-responsibilities (accessed 15 February 2016).

2. Peden M, Oyegbite K, Ozanne-Smith J, et al., eds. World Report on Child Injury Prevention. Geneva: World Health Organization and United Nations Children's Fund, 2008.

Krug EG, Dahlberg LL, Mercy JA, Zw A, Lozano, R. World Report on Violence and Health. Geneva: World Health Organization, 2002

4. Peden M, Hyder AA. Time to keep African kids safer. S Afr Med J 2009;99(1):36-37.

5. American Psychiatric Association. Psychiatric effects of media violence. APA fact sheet series. APA online public information. http://www.psych.org/public_info_media_violence.html (accessed 18 January 2017).

6. Osofsky JD. The impact of violence on children. The future of children. Domestic Violence Child 1999;9(3):33-49. http://dx.doi.org/10.2307/1602780

7. Congressional Public Health Summit. Joint Statement on the impact of entertainment violence on

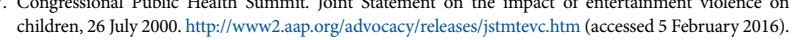
8. Peterson L, Brown D. Integrating child injury and abuse/neglect research: Common histories, etiologies, and solutions. Psychol Bull 1993;116(2):293-315. http://dx.doi.org/10.1037/0033-2909.116.2.293

9. Cunradi CB, Caetano R, Schafer I. Alcohol-related problems, drug use, and male intimate partner violence severity among US couples. Alcohol Clin Exp Res 2002;26(4):493-500. http://dx.doi.org/10.1097/00000374200204000-00009
}

S Afr Med J 2017;107(3):180-181. DOI:10.7196/SAMJ.2017.v107i3.12251 